\title{
Management and outcome of severe head injuries in the Trent region 1985-90
}

\author{
A C Elias-Jones, J A G Punt, A E Turnbull, T Jaspan
}

\begin{abstract}
In a five year period, 39 children ( 29 boys, 10 girls) aged 2 months to 13 years (mean 7.8 years) were studied who had suffered a major head injury (29 road traffic accidents, six falls, and four non-accidental injury). The injury had been assessed clinically and by cranial computed tomography or cranial ultrasound (in a single baby of 2 months). Initial Glasgow coma scores for all subjects ranged from 3-11 (mean 5.5), intact survivors 5-11 (7.4), minor handicap 4-11 (6.1), major handicap 3-6 (4.3), fatalities 3-6 (4.1). All were treated with sedation, paralysis, hyperventilation (arterial carbon dioxide tension $3.0-3.5 \mathrm{kPa}$ ), intracranial pressure monitoring and moderate body surface hypothermia to $32^{\circ} \mathrm{C}$. Nine children died and 30 survived (nine intact, 13 minor disability, and eight major disability). The worst cerebral perfusion pressure was over $40 \mathrm{~mm} \mathrm{Hg}$ in all but one survivor, and less than $40 \mathrm{~mm} \mathrm{Hg}$ in seven of nine fatalities. Severe hypocapnia both in the first 24 hours and overall was correlated with poor outcomes (dead or major disability), as were bilateral contusions or diffuse axonal injury.
\end{abstract}

(Arch Dis Child 1992;67:1430-5)

There is some evidence that control of raised intracranial pressure after major head injury can reduce mortality and improve the quality of survival. ${ }^{1-4}$ Most treatment protocols advocate hyperventilation to reduce arterial carbon dioxide tension $\left(\mathrm{PaCO}_{2}\right)$, sedation with opioids and benzodiazepines, and in resistant cases barbiturate administration to reduce cerebral metabolism and to control intracranial pressure and maintain cerebral perfusion pressure (mean arterial pressure less intracranial pressure) above $50 \mathrm{~mm} \mathrm{Hg}$ when possible and always above $40 \mathrm{~mm} \mathrm{Hg}{ }^{5-7}$ However, with barbiturate coma estimation of brain death is invalidated. Consequently, we have managed seriously head injured children without barbiturate coma but in substitution have used body surface cooling using a cooling mattress to bring the surface temperature down to $32^{\circ} \mathrm{C}$, thereby enabling greater control of intracranial pressure.

Subjects and methods

Thirty nine children ( 29 boys, 10 girls), aged 2 months to 13 years $(7 \cdot 8$ years) were treated. The children presented in the Trent region over 1985-90 with major head injuries that resulted from road traffic accidents in 29 (25 as cyclist or pedestrians and four within cars), from falls in six, and non-accidental injury in four. The Glasgow coma scale scores at presentation varied from 3-11 (mean 5.5), and are related to final outcomes in table 1 . All were thought clinically to be showing signs of raised intracranial pressure. One baby of 2 months had an extracerebral collection noted on ultrasound. One patient had extensive calvarial fractures with cranial sutural diastasis and subluxation of the cervical spine, and thus was not scanned. The remaining 37 had cranial computed tomograms, and of these 36 were reported as abnormal. A retrospective analysis of 32 of these 37 scans was performed by two radiologists (TJ and AET) who were not given the patient outcomes, to look for features on these scans that might predict adverse outcome, and were then correlated to the actual outcomes. The scans of five patients were untraceable.

The patients were all treated at the Queen's Medical Centre children's intensive care unit.

The treatment protocol included hyperventilation aiming for a $\mathrm{PaCO}_{2}$ of $3.0-3.5 \mathrm{kPa}$, body surface cooling, using a water cooling mattress, to $32^{\circ} \mathrm{C}$ using an American Medical Systems Rk325 K Thermia EC 300 temperature control. All patients received analgesia with morphine by infusion (loading dose $100-200 \mu \mathrm{g} / \mathrm{kg}$, then $20-40 \mu \mathrm{g} / \mathrm{kg} / \mathrm{hour}$ ) and sedation with midazolam $(60-240 \mu \mathrm{g} / \mathrm{kg} /$ hour) except the first patients in the study who received other benzodiazepines, principally Diazemuls (Dumex). All patients were paralysed with atracurium 300 $1200 \mu \mathrm{g} / \mathrm{kg} / \mathrm{hour}$, except the first patients in whom pancuronium was used. Intracranial pressure was monitored using a precoronal Richmond screw in 34 patients, subdural catheters in three, and not directly in two patients with extensive cranial fractures with suture diastasis. The pressure line was recorded on a Simonsen and Weel 8041 recorder. Arterial pressures were calculated by an S and W Pressure Module attached to an indwelling radial arterial cannula. The cerebral perfusion pressure was recorded by subtraction of the intracranial pressure from mean arterial pressure. Medical intervention was required if the intracranial pressure rose above $20 \mathrm{~mm} \mathrm{Hg}$, or the cerebral perfusion pressure fell below $50 \mathrm{~mm}$

Table 1 Initial Glasgow coma scale (maximum=14)

\begin{tabular}{lcll}
\hline & Frequency & Range & Mean \\
\hline Normal & 9 & $5-11$ & $7 \cdot 4$ \\
Minor handicap & 13 & $4-11$ & $6 \cdot 1$ \\
Major handicap & 8 & $3-6$ & $4 \cdot 3$ \\
Fatalities & 9 & $3-6$ & $4 \cdot 1$ \\
All subjects & 39 & $3-11$ & $5 \cdot 5$
\end{tabular}


Hg. The patients were initially maintained on $50 \%$ normal maintenance requirements of fluids, and if prolonged monitoring was anticipated, total parenteral nutrition was started via a central venous catheter.

This process was reversed if the patient was thought to have suffered brain stem death, so that formal testing could be carried out, or after five days if the patient was in a stable condition. If, on warming the patient, intracranial pressure became unstable the process was recommenced for a further five days. If warming to $37^{\circ} \mathrm{C}$ was uneventful, normocapnia was allowed and then, if the patient was stable, the sedation was reversed, the intracranial pressure line removed, and the patient extubated and rehabilitation begun.

Outcome was assessed in four broad categories: neurological, cognitive, behavioural, and the presence of post-traumatic epilepsy. The surviving patients have been followed up for six months to five years, mean 2.5 years.

\section{Results}

The patients were divided into four groups according to outcome: intact survivors, those with minor or with major handicaps, and fatalities. Nine patients died and nine have survived intact. Twenty one patients have a degree of residual disability. Thirteen were assessed as having a minor handicap (table 2a). Two of these patients are currently undergoing rehabilitation and are anticipated to return to normality. Eight have been classified as suffering major disability with mental retardation and either spastic quadriplegia or hemiplegia (table 2b). Two of these were, however, neurologically abnormal before the injury.

The correlation between the outcomes and lowest mean blood pressure, highest intracranial pressure, lowest cerebral perfusion pressure, and lowest $\mathrm{PaCO}_{2}$ are shown in table 3 and figs $1-3$. There were significant differences

Table 2 Type of minor (a) or major (b) disability

\begin{tabular}{lc}
\hline (a) Minor disability (present in 33.3\% of study group) \\
Clumsy & 2 \\
Poor concentration/memory & 3 \\
Controlled post-traumatic epilepsy & 1 \\
Behavioural problems & 2 \\
Minor neurological signs & 3 \\
Problems walking* & 2 \\
Total & 13
\end{tabular}

(b) Major disability (present in $20.5 \%$ of study group) Spastic quadriplegia, dysarthria,

retarded

pastic hem

$$
\text { Total }
$$$$
\begin{aligned}
& 4 \\
& 8
\end{aligned}
$$

"Probably will be normal.

tTwo children neurologically abnormal before injury.

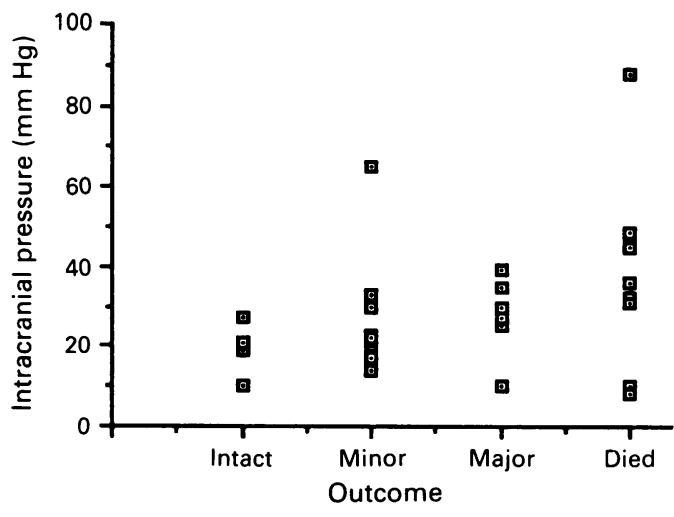

Figure 1 Intracranial pressure.

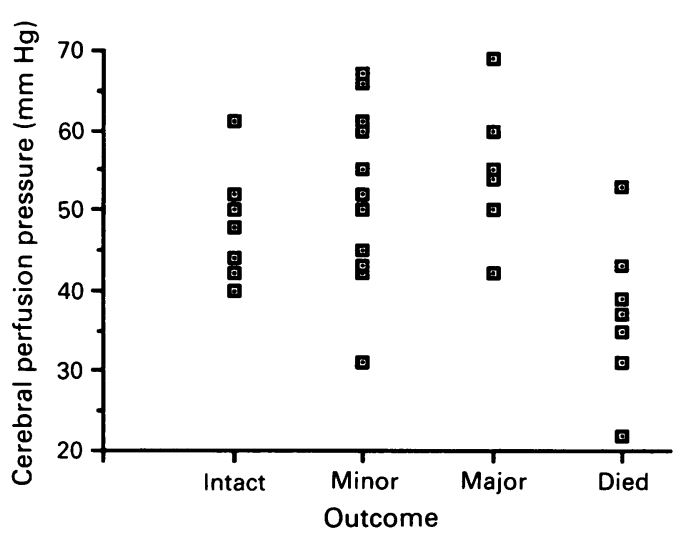

Figure 2 Cerebral perfusion pressure.

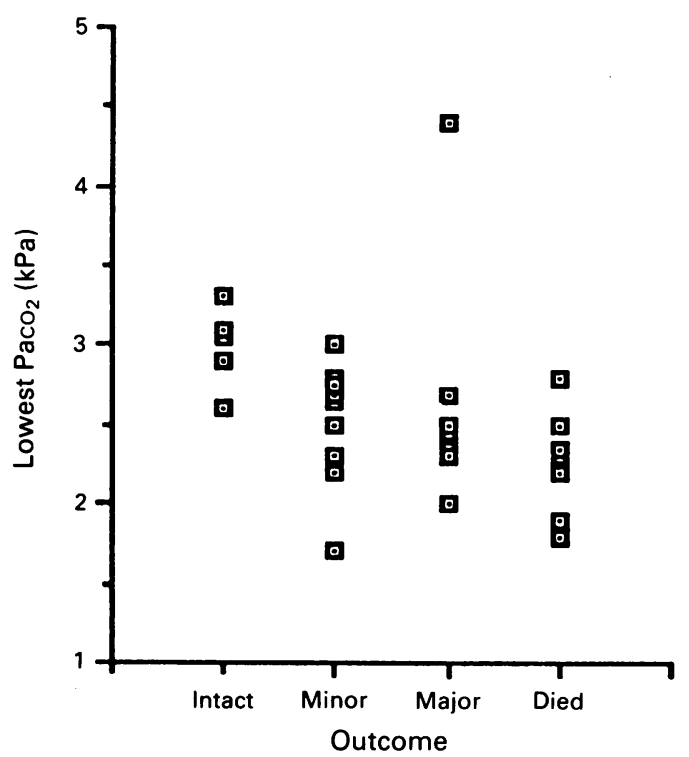

Figure 3 Lowest $\mathrm{PaCO}_{2}$ in first 24 hours.

Table 3 Relations of outcome to blood pressure, intracranial pressure, cerebral perfusion pressure, hypoxia (low Pa( $\left.)_{2}\right)$, hypocarbia (low $\left.\mathrm{PaCO}_{2}\right)$. Results are range (mean)

\begin{tabular}{|c|c|c|c|c|c|}
\hline Outcome & $\begin{array}{l}\text { Lowest mean } \\
\text { blood pressure } \\
(\mathrm{mm} \mathrm{Hg})\end{array}$ & $\begin{array}{l}\text { Highest mean } \\
\text { intracranial pressure } \\
(\mathrm{mm} \mathrm{Hg})\end{array}$ & $\begin{array}{l}\text { Lowest mean } \\
\text { cerebral perfusion } \\
\text { pressure } \\
(\mathrm{mm} H \mathrm{Hg})\end{array}$ & $\begin{array}{l}\text { Lowest mean } \\
P_{a(;)} \\
(k P a)^{2}\end{array}$ & $\begin{array}{l}\text { Lowest Paci), } \\
(\mathrm{kPa})\end{array}$ \\
\hline $\begin{array}{l}\text { Intact survivor } \\
\text { Minor handicap } \\
\text { Major handicap } \\
\text { Fatalities }\end{array}$ & $\begin{array}{l}48-80(60 \cdot 4) \\
30-92(65 \cdot 2) \\
47-100(68 \cdot 4) \\
40-75(51 \cdot 5)\end{array}$ & $\begin{aligned} 10-27 & (18 \cdot 8) \\
14-65 & (24 \cdot 8) \\
10-39 & (27 \cdot 3) \\
8-88 & (38 \cdot 5)^{*}\end{aligned}$ & $\begin{array}{l}42-70(50 \cdot 6) \\
31-67(51 \cdot 7) \\
42-69(54 \cdot 6) \\
22-53(34 \cdot 5)^{1}\end{array}$ & $\begin{array}{l}6 \cdot 3-13 \cdot 1(9 \cdot 1) \\
6 \cdot 2-10 \cdot 6(9 \cdot 3) \\
6 \cdot 4-10 \cdot 0(7 \cdot 9) \\
5 \cdot 8-18 \cdot 0(9 \cdot 9)\end{array}$ & $\begin{array}{l}2 \cdot 3-3 \cdot 3(2 \cdot 8) \\
2 \cdot 2-3 \cdot 1(2 \cdot 7) \\
2 \cdot 1-4 \cdot 4(2 \cdot 6) \\
1 \cdot 8-2 \cdot 8(2 \cdot 3)^{*}\end{array}$ \\
\hline
\end{tabular}

"p less than 0.05. 
in cerebral perfusion pressure between intact survivors and fatalities $(\mathrm{p}<0.05)$, and similarly for intracranial pressure and the lowest $\mathrm{PaCO}_{2}$ recorded. No differences were observed in arterial oxygen tension $\left(\mathrm{PaO}_{2}\right)$, lowest mean blood pressure, and initial haemoglobin concentrations. Fifteen out of 30 patients who survived received total parenteral nutrition (TPN) for an average of 10 days. Two of the nine patients who died received TPN. The complications occurring during treatment are listed in table 4, with pneumonia most common in 25 of the 39 patients, including 21 of the 30 survivors $(70 \%)$,

Table 4 Main complication

\begin{tabular}{lr}
\hline Complication & No \\
\hline Pneumonia & 25 \\
Pneumothorax & 4 \\
Convulsions & 9 \\
Postextubation stridor & 6 \\
Diabetes insipidus & 2 \\
Morphine withdrawal & 2 \\
Infections & 2 \\
$\quad$ Urine & 1 \\
Septic arthritis & 1 \\
Septicaemia & 1 \\
\hline
\end{tabular}

Table 5 Appearances on computed tomography (retrospective analysis)

\begin{tabular}{|c|c|c|c|c|}
\hline & $\begin{array}{l}\text { No of } \\
\text { patients }\end{array}$ & $\begin{array}{l}\text { Good } \\
\text { (normal + minor) }\end{array}$ & $\begin{array}{l}\text { Poor } \\
\text { (major) }\end{array}$ & Died \\
\hline \multicolumn{5}{|c|}{ (a) Clinical outcome associated with radiological indices of intracranial tension } \\
\hline Normal third ventricle and cisterns & 10 & 9 & 1 & 0 \\
\hline One or both compressed & 12 & 4 & 4 & 4 \\
\hline One or both obliterated & 10 & 4 & 3 & 3 \\
\hline \multicolumn{5}{|c|}{ (b) Clinical outcome associated with parenchymal lesions } \\
\hline Unilateral & 7 & 5 & 1 & 1 \\
\hline Bilateralt & 7 & 1 & 3 & 3 \\
\hline Diffuse axonal injury & 9 & 4 & 2 & 3 \\
\hline Raised intracranial pressure & 4 & 2 & 2 & 0 \\
\hline Normal & 5 & 5 & 0 & 0 \\
\hline
\end{tabular}

Unilateral equals contusions in one cerebral hemisphere or an ipsilateral cerebellar hemisphere. tBilateral equals contusions in both cerebral or cerebellar hemispheres.

$\ddagger$ Raised intracranial pressure without parenchymal lesions.

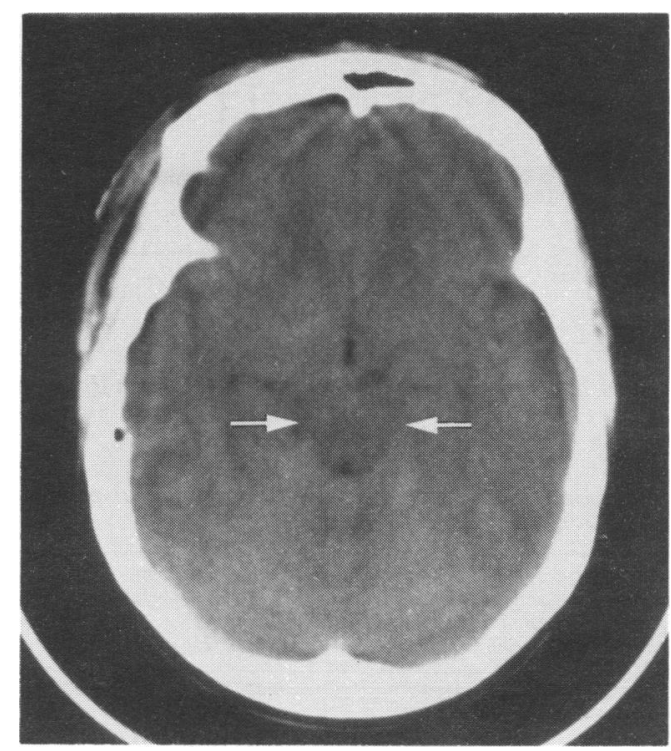

Figure 4 Computed tomogram showing early raised intracranial pressure and obliteration of the ambient cisterns. as defined by radiographic changes, bacterial isolation, increased secretions, and increased oxygen requirements.

Analysis of 32 available computed tomograms at the end of the study by two radiologists performed blind to the clinical information was then correlated with outcomes (table 5). Particular attention was paid to signs of raised intracranial pressure (figs 4 and 5 ), the size of the basal cisterns and third ventricles (fig 6), to the presence of unilateral (fig 7) or bilateral contusions (fig 8), and to diffuse axonal injury (figs 9 and $10 \mathrm{~A}-\mathrm{D}$ ). In contrast figure 11 demonstrates no significant intracranial lesion despite a skull fracture following a serious head injury. When the basal cisterns and third

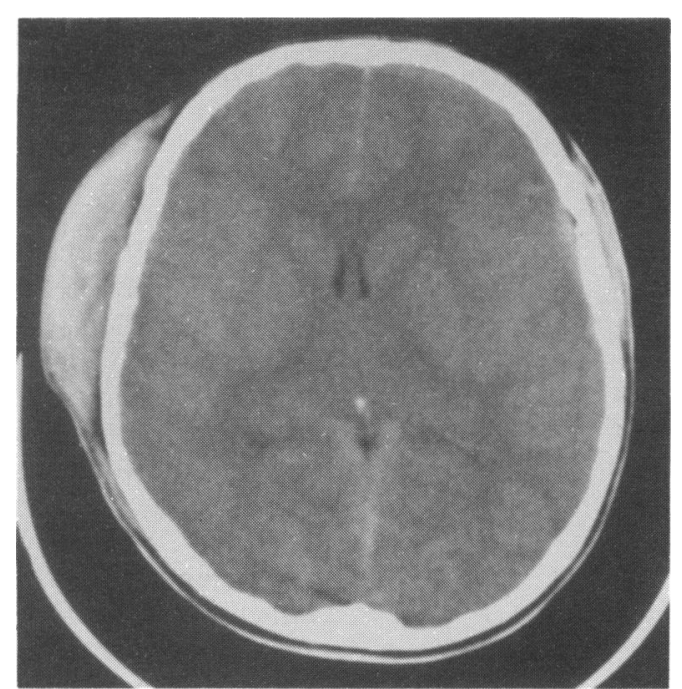

Figure 5 Computed tomogram showing later raised intracranial pressure, obliteration of the third ventricle, and slit-like compressed lateral ventricles. A large subgaleal haematoma is present in the right frontotemporal region.

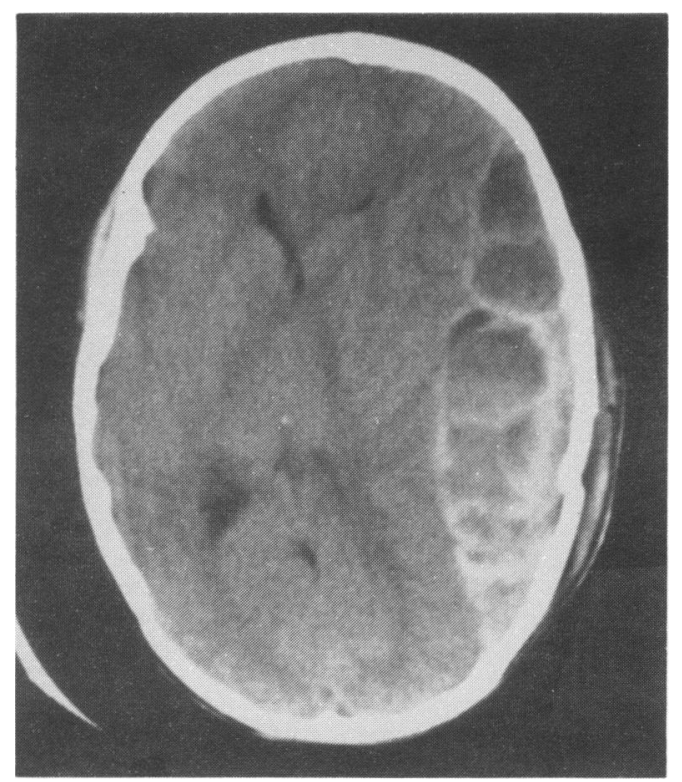

Figure 6 Computed tomogram showing a large acute left frontotemporo-occipital extradural haematoma with marked mass effect and obliteration of the third ventricle. Note internal loculations and pseudomembranes. 
ventricle were normal $90 \%$ of patients had a good outcome (normal or minor disability) whereas if compressed or obliterated $32 \%$ had major handicap and $32 \%$ died. When unilateral contusions occurred $71 \%$ had a good outcome, but with bilateral contusions only $14 \%$ had a good outcome. If diffuse axonal injury was noted $56 \%$ had a poor outcome. In the three patients with diffuse axonal injury and contusions all had a poor outcome.

\section{Discussion}

The results of this study compare favourably with other reported series, with $56 \%$ making a

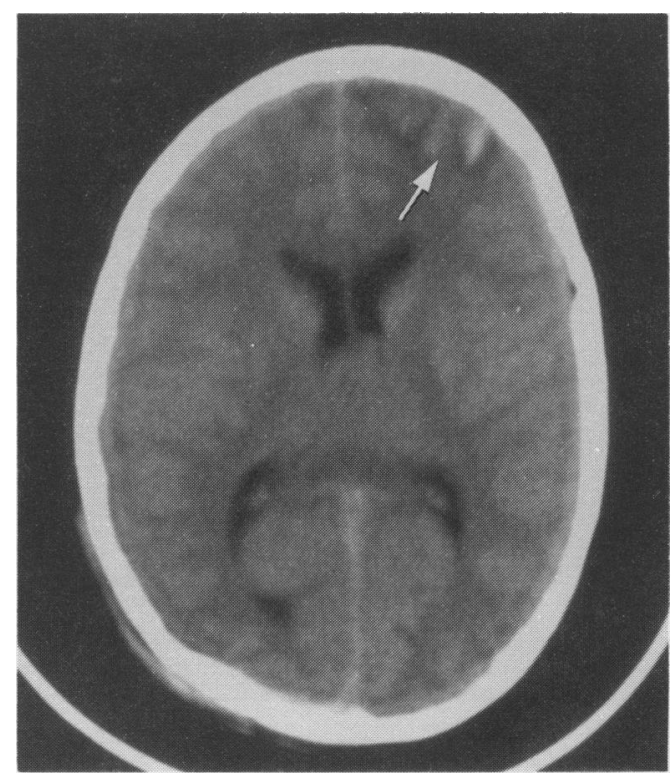

Figure 7 Computed tomogram showing a unilateral left frontal haemorrhagic contusion (arrow).

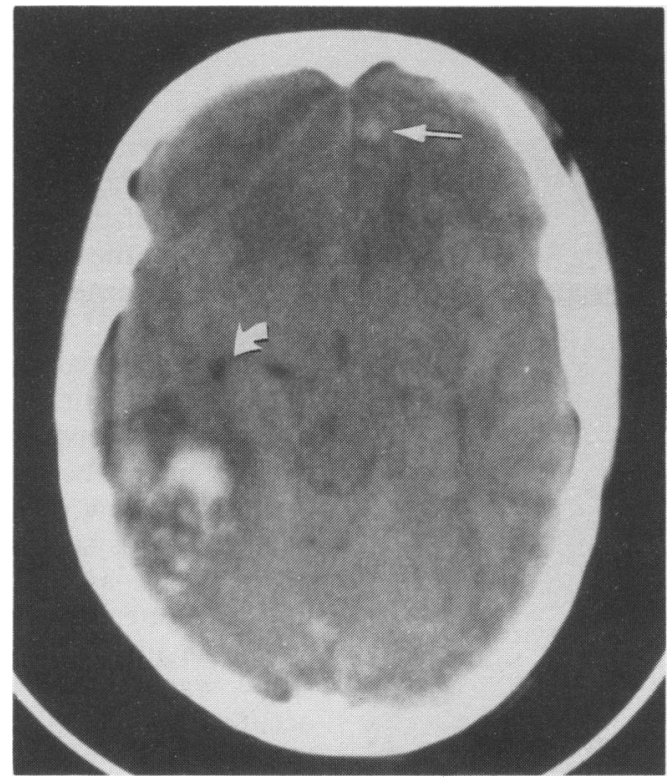

Figure 8 Computed tomogram showing a small left frontal haemorrhagic contusion (straight arrow) and a large right temporo-occipital haemorrhagic contusion. The temporal horm of the right lateral ventricle is distorted by the local mass effect (curved arrow). good recovery with normal outcome or minor disability only compared with $36 \%$ reported by Becker $e t \mathrm{al}^{2}$ and $45 \%$ in the series of Marshall et $a l^{1}$ (table 6). As in other series ${ }^{8}$ the majority of our patients had been struck by motor vehicles.

The use of surface cooling enabled the avoidance of barbiturate coma, and this meant that assessment of brain stem death could be made earlier. When confirmed this would enable earlier donor organ retrieval, and may improve the likelihood of successful donation from such unstable patients.

The observation that intracranial pressure was highest in non-survivors was not surprising, nor was the lower cerebral perfusion pressures in this group. The approximate cut off of $40 \mathrm{~mm} \mathrm{Hg}$ for cerebral perfusion pressure delineating survivors and non-survivors was in accordance with previous studies. ${ }^{9}$

Analysis has demonstrated a poorer survival with lower $\mathrm{PaCO}_{2}$ in the first 24 hours. Similar findings have been reported, ${ }^{10}$ suggesting that excessive hyperventilation early on after head injury may reduce cerebral blood supply below a level necessary to nurture the basal metabolic level of an already insulted brain. Although the numbers studied here were small, further analysis of possibly harmful hyperventilation in such critically injured patients is required. We would suggest frequent blood gas analysis, the use of end tidal carbon dioxide measurements and caution with over enthusiastic hand ventilation

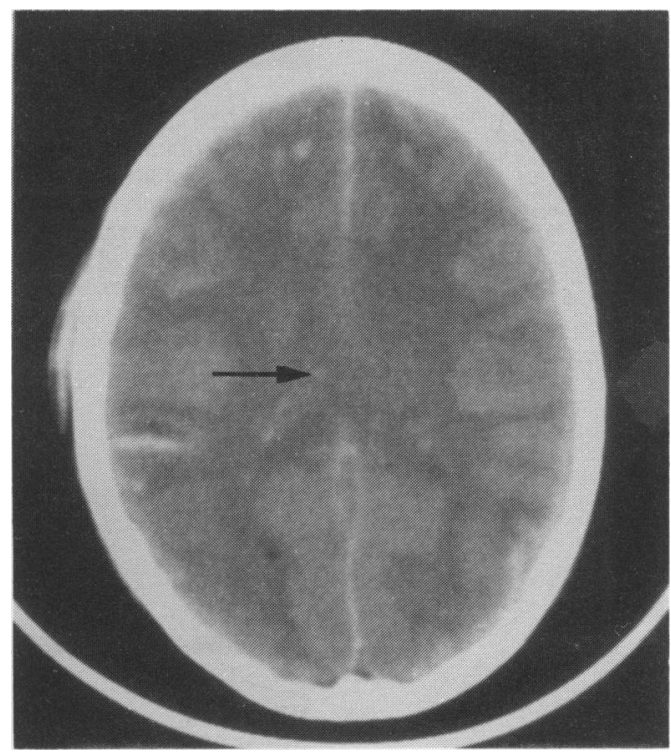

Figure 9 Computed tomogram showing diffuse axonal injury and widespread cortical and subcortical haemorrhagic contusions in both cerebral hemispheres. Note also a subtle typical haemorrhagic contusion in the region of the body of the corpus callosum (arrow).

Table 6 Outcome comparison with other studies (\%)

\begin{tabular}{llll}
\hline & $\begin{array}{l}\text { Becker } \\
\text { et al } \\
(n=160)\end{array}$ & $\begin{array}{l}\text { Marshall } \\
\text { et al } \\
(n=100)\end{array}$ & $\begin{array}{l}\text { Elias-7ones } \\
\text { et al } \\
(n=39)\end{array}$ \\
\hline $\begin{array}{l}\text { Good recovery } \\
\text { Moderate disability }\end{array}$ & 36 & 45 & 56 \\
$\begin{array}{l}\text { Severe disability } \\
\text { Died }\end{array}$ & 10 & 15 & 21 \\
\hline
\end{tabular}



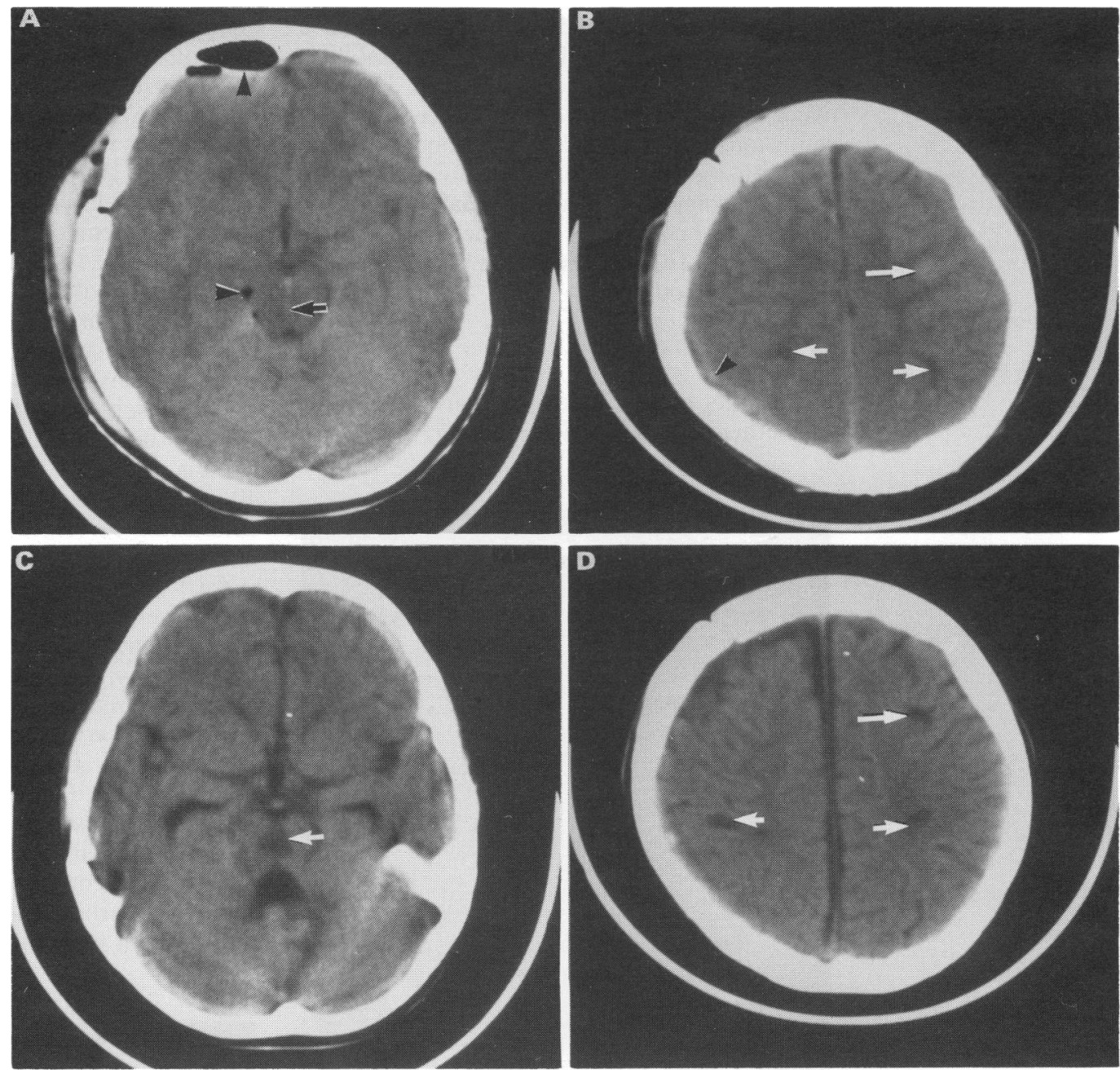

Figure 10 (A) Computed tomogram showing an example of diffuse axonal injury; a compound right temporal bone fracture with intracranial air overlying the right frontal pole and in the right ambient cistern is shown by arrowheads. Note early subtle brain stem contusion (small arrow). (B) Same patient showing gyral contusion in the left posterior frontal region (arrow). Note a thin right convexity subdural haematoma (arrowhead) and small subcortical white matter linear lesions (small arrows).

(C) Same patient four weeks later showing that encephalomalacic lesion has developed centrally within brain stem (arrow).

Note development of generalised atrophy in both the supratentorial and infratentorial compartments with dilatation of temporal horns, basal cisterns, and fourth ventricle, (D) Part of the same scan as $(C)$ showing a focal area of encephalomalacia has developed at the site of the left posterior frontal gyral lesion (arrow). Further subcortical white matter lesions are once again seen possibly representing gliding lacerations (small arrows).

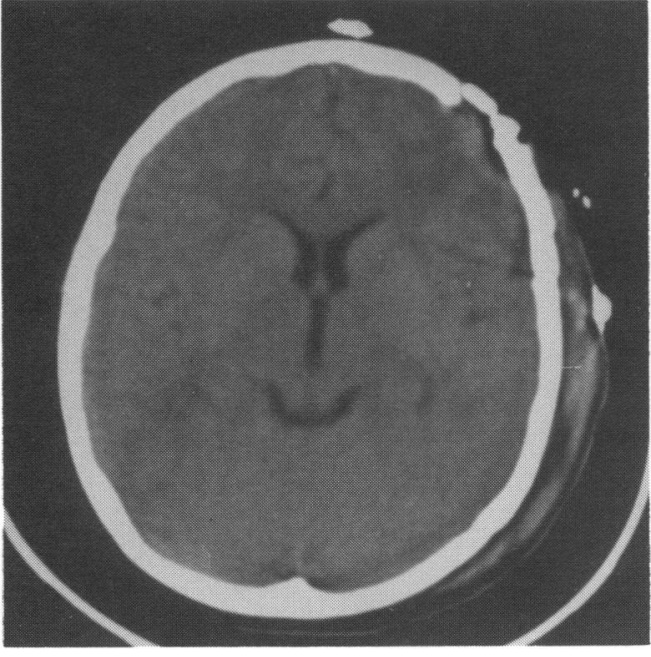

Figure 11 Computed tomogram showing a normal brain scan after serious head injury consequent to a heavy blow from a blunt instrument causing a comminuted left frontal fracture. There is no significant intracranial lesion present. of such patients, aiming for a $\mathrm{PaCO}_{2}$ in the band of $3 \cdot 5-4 \cdot 0 \mathrm{kPa}$.

Analysis of the computed tomogram appearances has borne out other studies that obliteration of basal cisterns and the third ventricle is a worrying sign. ${ }^{11} 12$ Combinations of contusions and diffuse axonal injury predict poor outcome in the few patients in this study.

The initial Glasgow coma scores, while showing a trend to be lower in patients with poor outcomes, show considerable overlap between patient groups such that they cannot be relied upon to act as a basis for withholding full intensive care treatment.

The incidence of pneumonia noted in this study was high; however this is a common occurrence in ventilated patients some of whom may also have aspirated at the time of injury. Although it is possible that surface cooling encourages pneumonic attack, the administration of antibiotics with physiotherapy dealt effectively with this complication, and did not prejudice survival. Many of the patients were 
also receiving cimetidine which is also known to encourage bacterial pneumonia, ${ }^{13}$ and has led us to turn to alternative protective agents.

\section{CONCLUSION}

This study has demonstrated that a policy of surface cooling is effective and obviates the need for barbiturates and all the concomitant problems associated with the latter.

Analysis of the initial Glasgow coma scores has shown considerable overlap; however a good outcome is expected if the score is 7 or more, whereas a score of 3 predicts death or severe permanent disability. A poor outcome is also associated with a low $\mathrm{PaCO}_{2}(<3.0 \mathrm{kPa})$ and a low cerebral perfusion pressure $(<40 \mathrm{~mm}$ $\mathrm{Hg}$ ). Consequently, maintenance of an adequate cerebral perfusion pressure over $50 \mathrm{~mm} \mathrm{Hg}$ should be a primary aim of the treatment protocol.

Radiological appearances that carry a poor prognosis are obliterations of the basal cisterns and third ventricle, bilateral hemispheric contusions and/or diffuse axonal injury.

1 Marshall LF, Smith RW, Shapiro HM. The outcome of aggressive treatment in severe head injuries. $\mathcal{F}$ Neurosurg 1979;50:20-5.

2 Becker DP, Miller JD, Ward JD, Greenberg RP, Young HF Sakalas $\mathbf{R}$. The outcome of severe head injury with early diagnosis and intensive management. $\mathcal{f}$ Neurosurg $1977 ; 47$ : diagnosis

3 Caniano DA, Nugent SK, Rogers MC, Haller JA. Intracranial pressure monitoring in the management of the pediatric trauma patient. F Pediatr Surg 1980;15:537-42.

4 Nordstrom CH, Sunbarg G, Messeter K, Schalen W. Severe traumatic brain lesions in Sweden. Brain Inj 1989;3:267-81.

5 Pierce EC, Lambertsen CJ, Deutsch S, et al. Cerebral circulation and metabolism during thiopental anaesthesia and hyperventilation in man. $\mathcal{f}$ Clin Invest 1962;41:1664-71

6 Shapiro HM, Wyte SR, Loeser J. Barbiturate-angmented hypothermia for reduction of persistent intracranial hypertension. F Neurosurg 1974;40:90-100.

7 Frewen TC, Sumabat WO, Han VK, Campbell K, Tiffin N. Effects of hyperventilation, hypothermia and altered blood viscosity on cerebral blood flow, cross-brain oxygen blood tion and ceral blood now, cross-brain oxygen extracMed 1989;17:912-6.

8 Sharples P M, Storey A, Aynsley-Green A, Eyre J A. Causes of fatal childhood accidents involving head injury in of fatal childhood accidents involving head injur
Northern region, 1979-86. BMF 1990;301:1193-7.

9 Goikein KJ, Amit Y, Mussaffi H. Intracranial pressure in coikein KJ, Amit $Y$, Mussaffi $H$. Intracranial pressure in
central nervous system infections and cerebral ischaemia of Infancy. Arch Dis Child 1983;58:184-6.

10 Jenkins JG, Glasgow JF, Black GW, et al. Reye's syndrome: assessment of intracranial monitoring. $B M \mathcal{F} 1987 ; 294$ 337-8.

11 Colquhoun IR, Burrows EH. The prognostic significance of the third ventricle and basal cisterns in severe closed head injury. Fournal of Clinical Radiology 1989;40:13-6.

12 Soanzerla EP, Tomei G, Guerra P, et al. Clinicoradiologial and therapeutic considerations in severe diffuse traumatic

13 Craven DE Kunches LM, Kilinsky V et al Risk factors for pneumonia and fatality in patients receiving continuous pneumonia and fatality in patients receiving continuous
mechanical ventilation. Am Rev Respir Dis 1986;133:792-6. 